\title{
Fire and forage quality: post-fire regrowth quality and pyric herbivory in subtropical grasslands of Nepal.
}

\author{
Shyam Kumar Thapa ${ }^{1}$, Joost de Jong ${ }^{2}$, Anouschka Hof ${ }^{1}$, Naresh Subedi ${ }^{3}$, Laxmi Joshi ${ }^{3}$, \\ and Herbert Prins ${ }^{4}$ \\ ${ }^{1}$ Wageningen University \& Research Wildlife Ecology and Conservation Group \\ ${ }^{2}$ Wageningen Universiteit en Researchcentrum \\ ${ }^{3}$ National Trust for Nature Conservation \\ ${ }^{4}$ Wageningen Universiteit en Research
}

January 12, 2022

\begin{abstract}
Indiscriminate fire is rampant throughout subtropical South and Southeast Asian grasslands. However, very little is known about the role of fire and pyric herbivory on the functioning of highly productive subtropical monsoon grasslands lying within Cwa-climatic region. We collected grass samples from $60 \mathrm{~m}$ x $60 \mathrm{~m}$ plots and determined vegetation physical and chemical properties at regular 30-day intervals from April to July 2020, starting from 30 days after fire to assess post-fire regrowth forage quality. We counted pellet groups for the same four months from $2 \mathrm{~m}$ x $2 \mathrm{~m}$ quadrats that were permanently marked with pegs along the diagonal of each $60 \mathrm{~m}$ x $60 \mathrm{~m}$ plot to estimate grazing intensity to the progression of post-fire regrowth. We observed strong and significant reductions in crude protein (mean value 9.1 to 4.1 [ $55 \%$ decrease]) and phosphorus (mean value 0.2 to 0.11 [ $45 \%$ decrease]) in forage collected during different time intervals i.e., from 30 days to 120 days after fire. Mesofaunal deer utilised the burned areas extensively for a short period, i.e., up to two months after fire when the burned areas contained short grasses with a higher level of crude protein and phosphorus. Grazing intensity of chital (Axis axis) to post-fire regrowth differed significantly over time since fire, with higher intensity of use at 30 days after fire. Grazing intensity of swamp deer (Rucervus duvaucelii) did not differ significantly until 90 days after fire, however, decreased significantly after 90 days since fire. Large-scale indiscriminate single event fires thus may not fulfil nutritional requirements of all species in mesofaunal deer community in these subtropical monsoon grasslands. We recommend for a spatio-temporal manipulation of fire to reinforce grazing feedback and to yield for the longest possible period a reasonably good food supply for the conservation of mesofaunal deer.
\end{abstract}

\section{Hosted file}

1. Manuscript.docx available at https://authorea.com/users/407342/articles/552525-fire-andforage-quality-post-fire-regrowth-quality-and-pyric-herbivory-in-subtropical-grasslandsof-nepal 

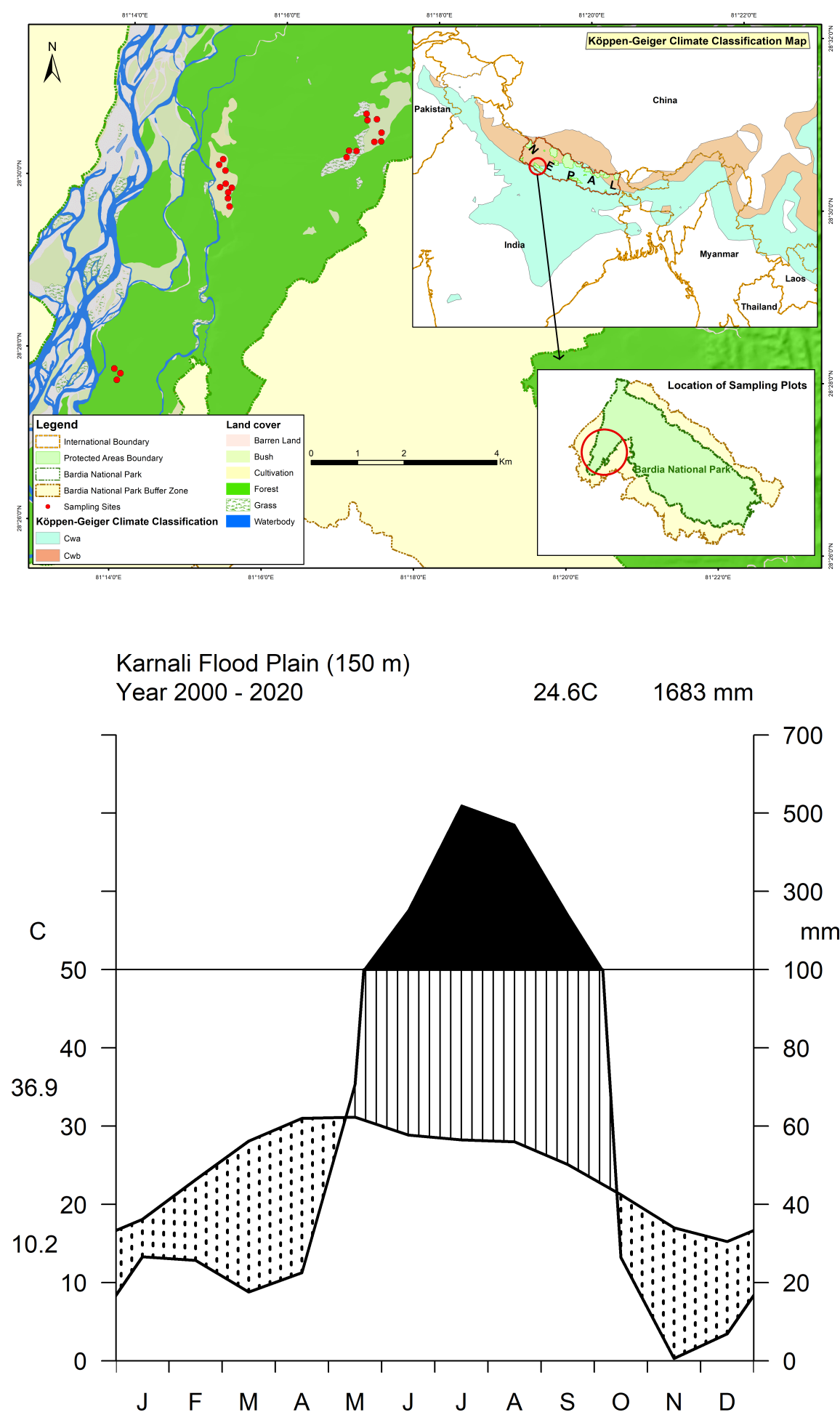

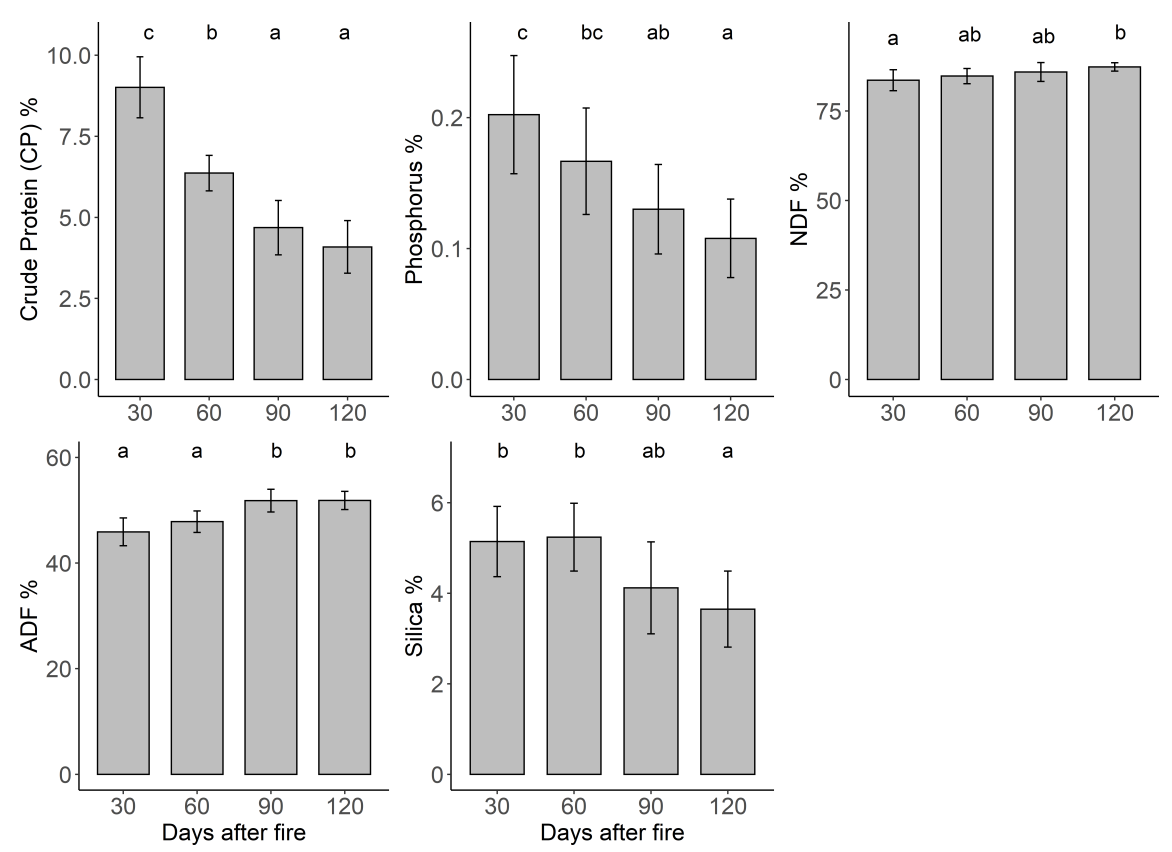


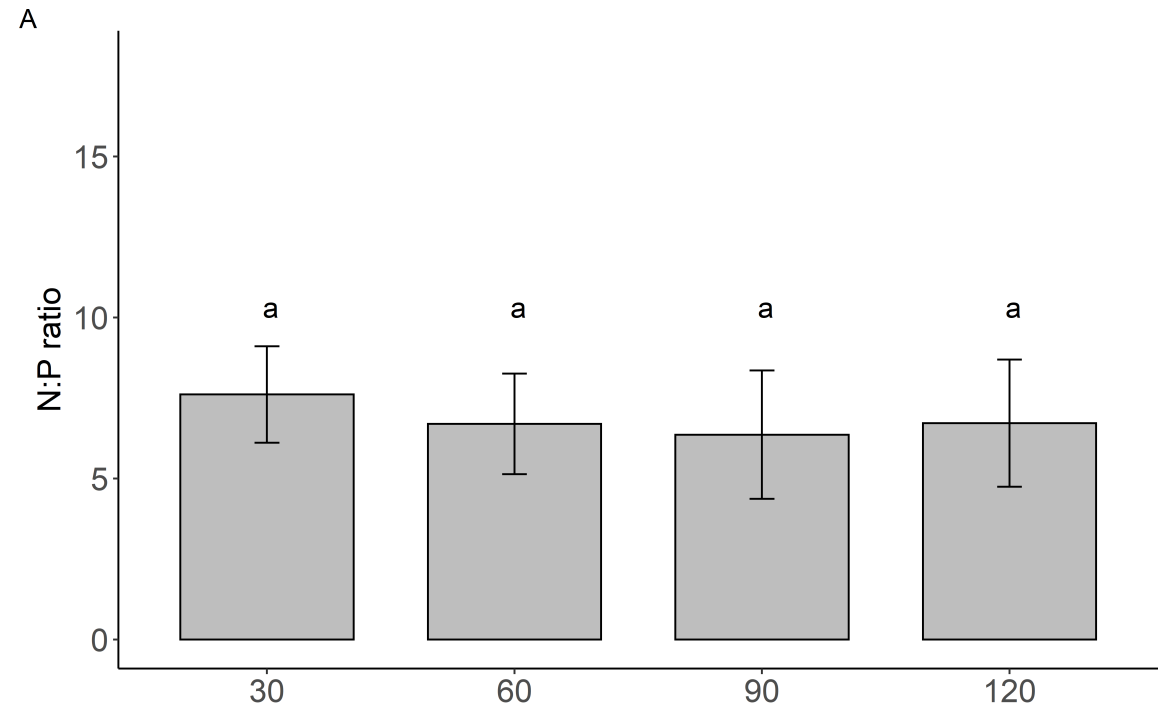

B

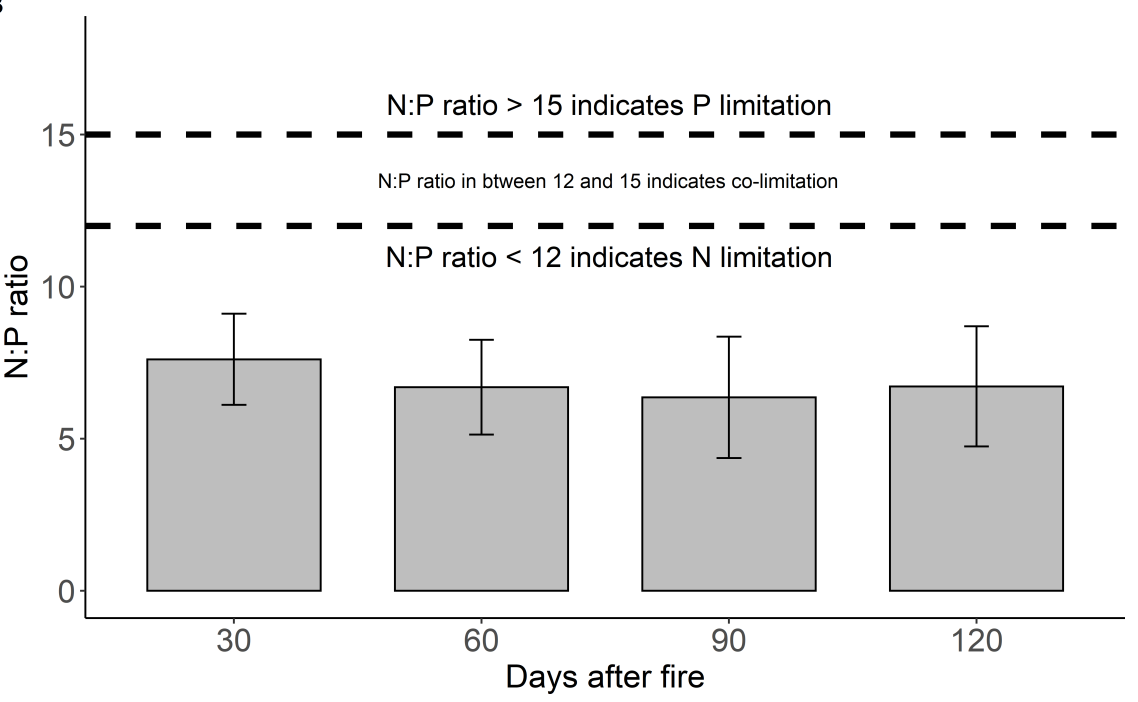



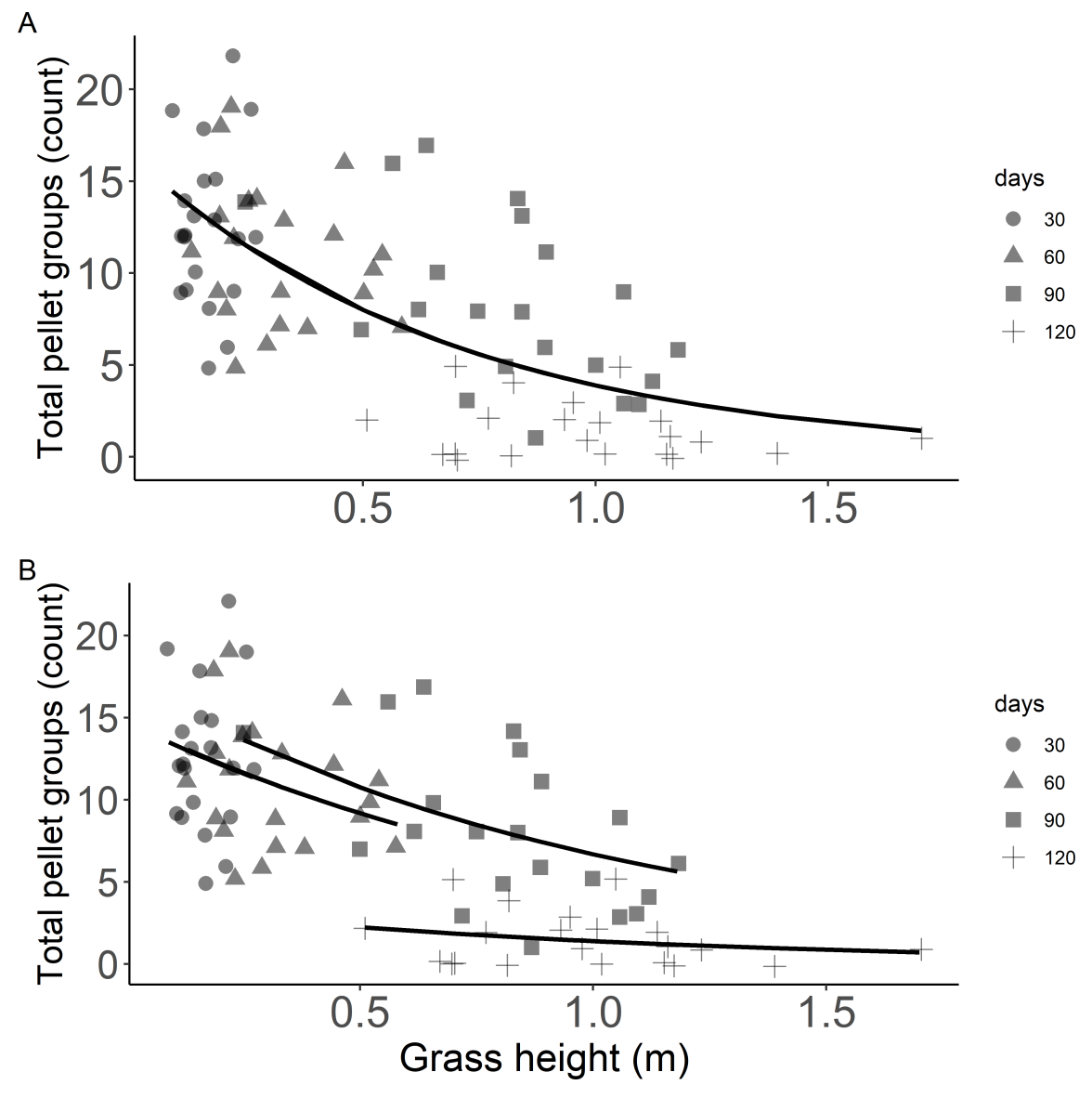


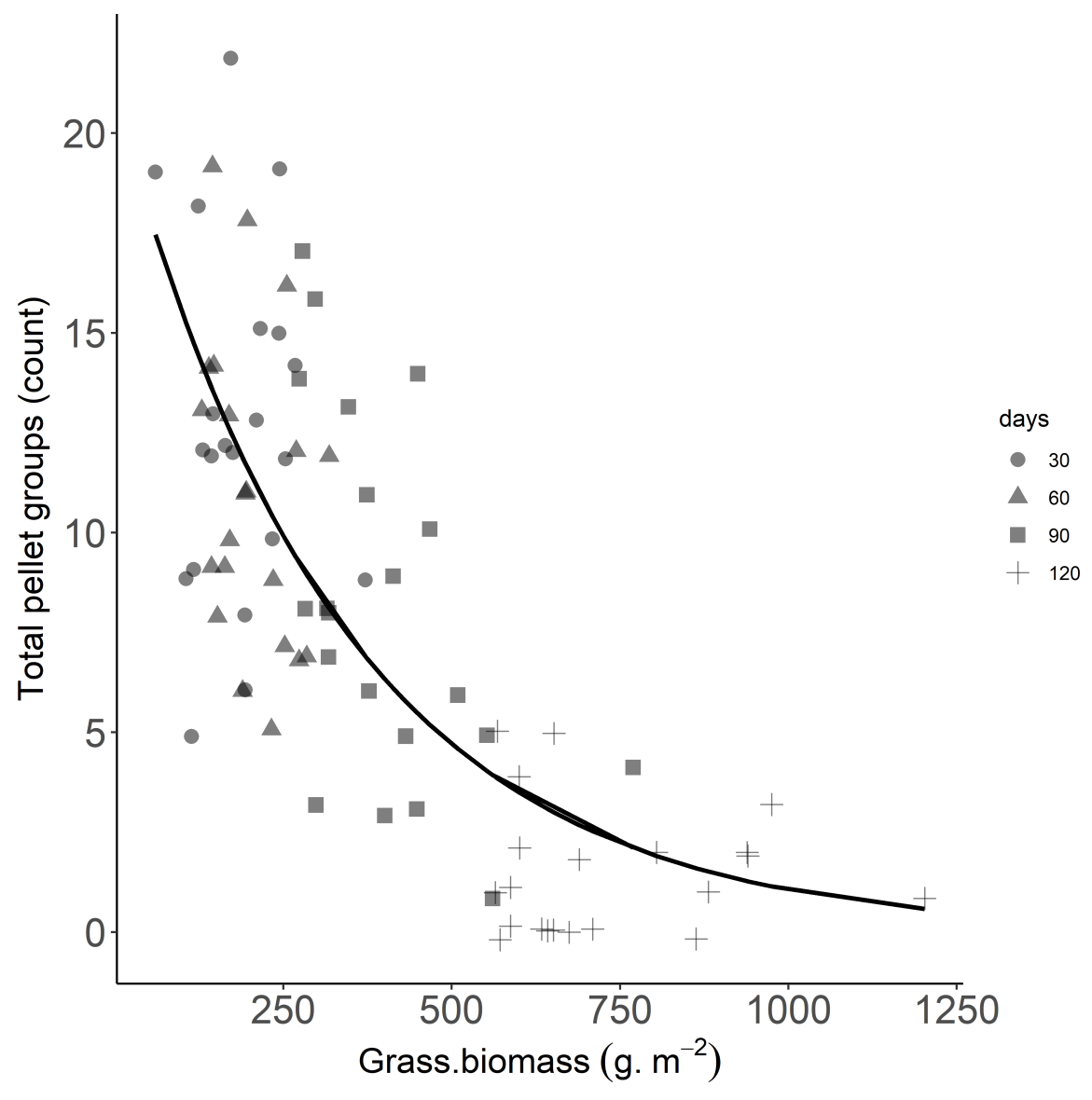




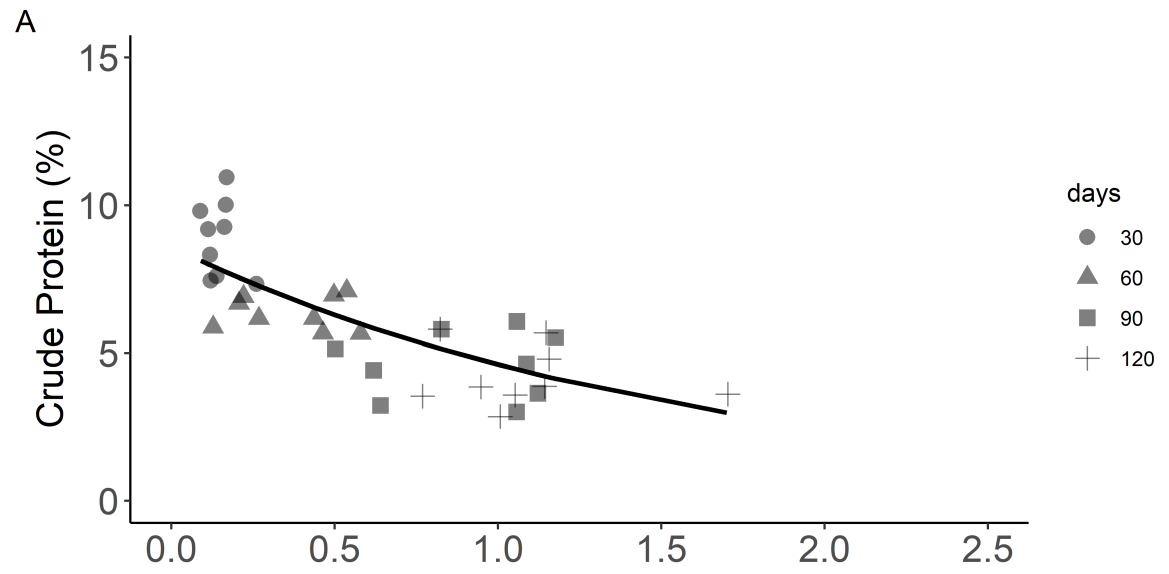

B

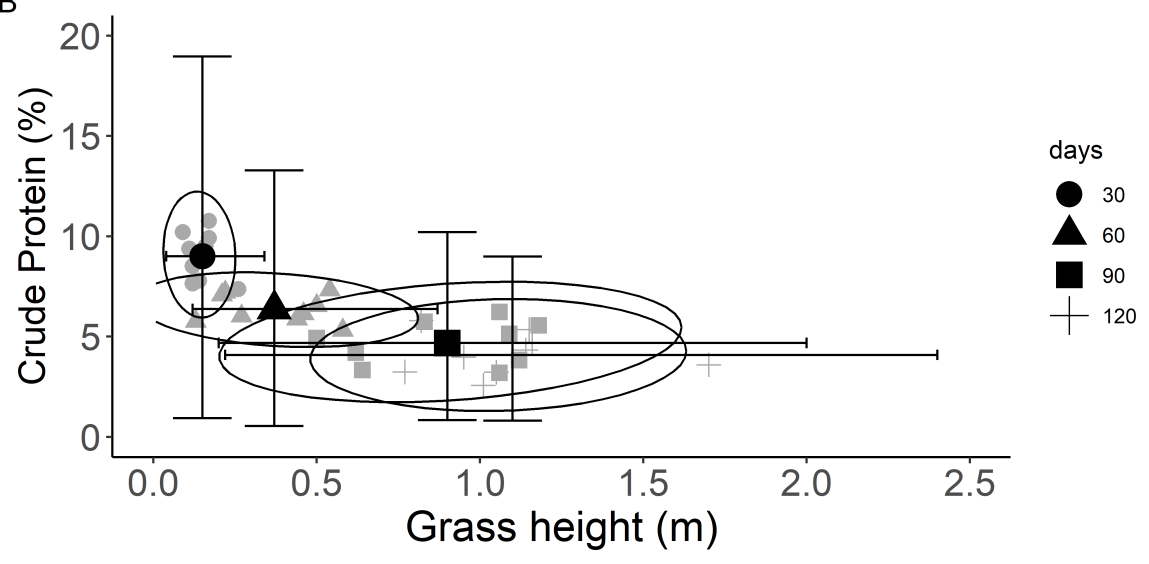



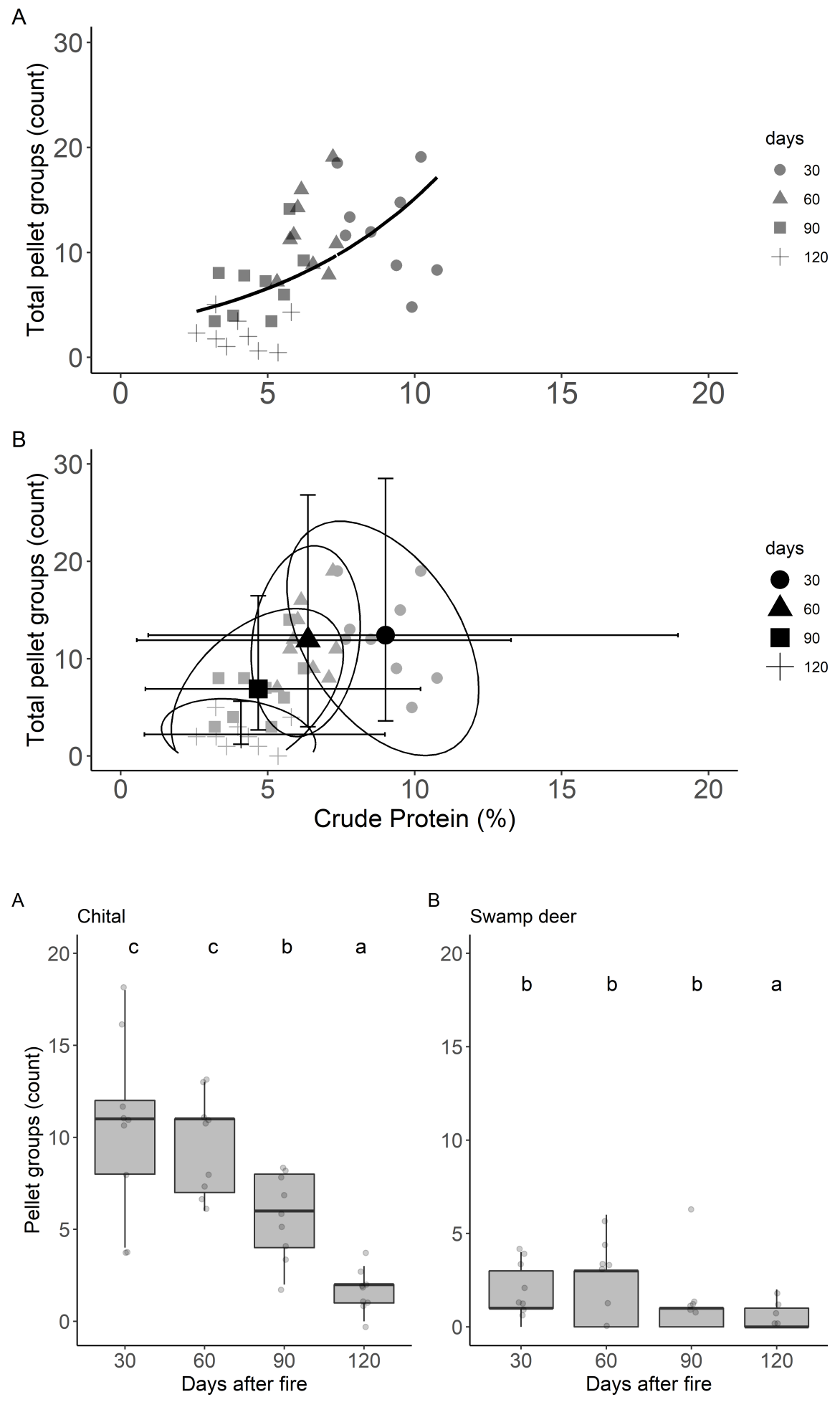


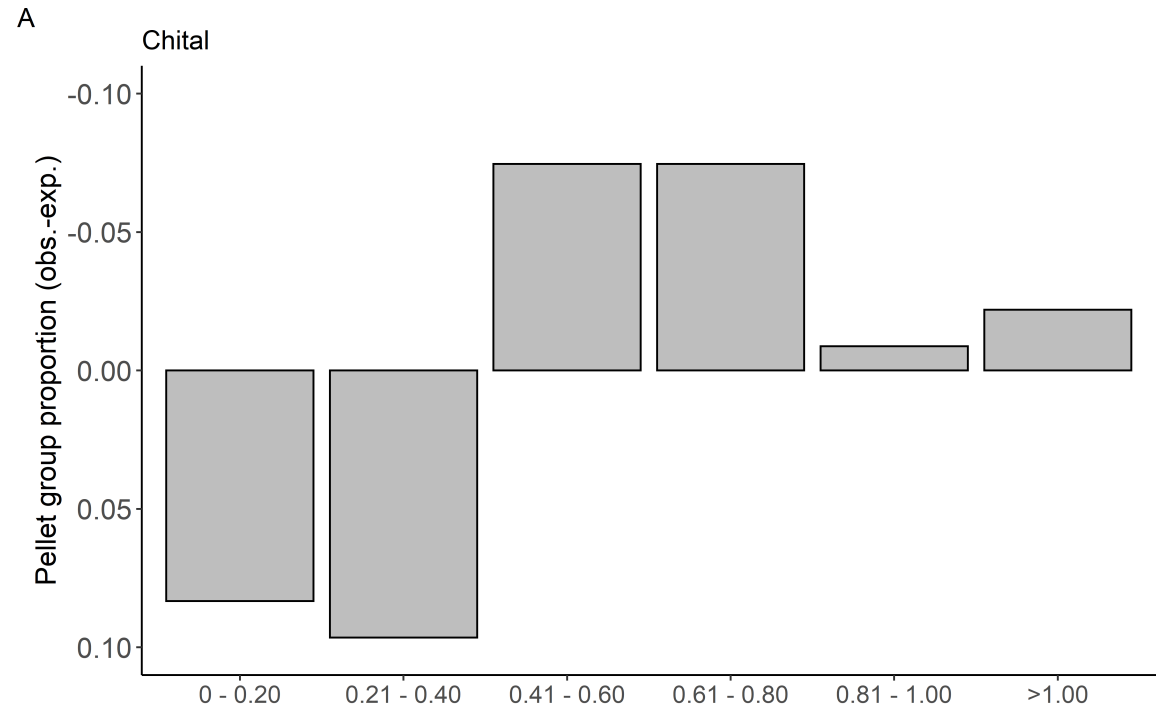

B

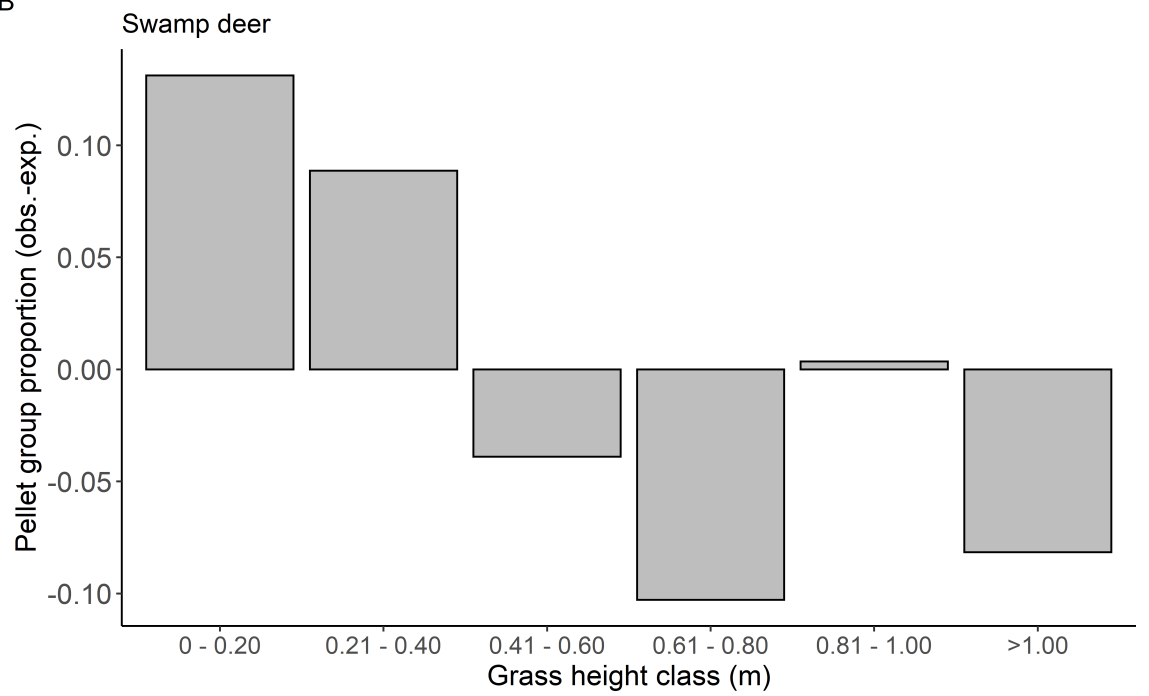



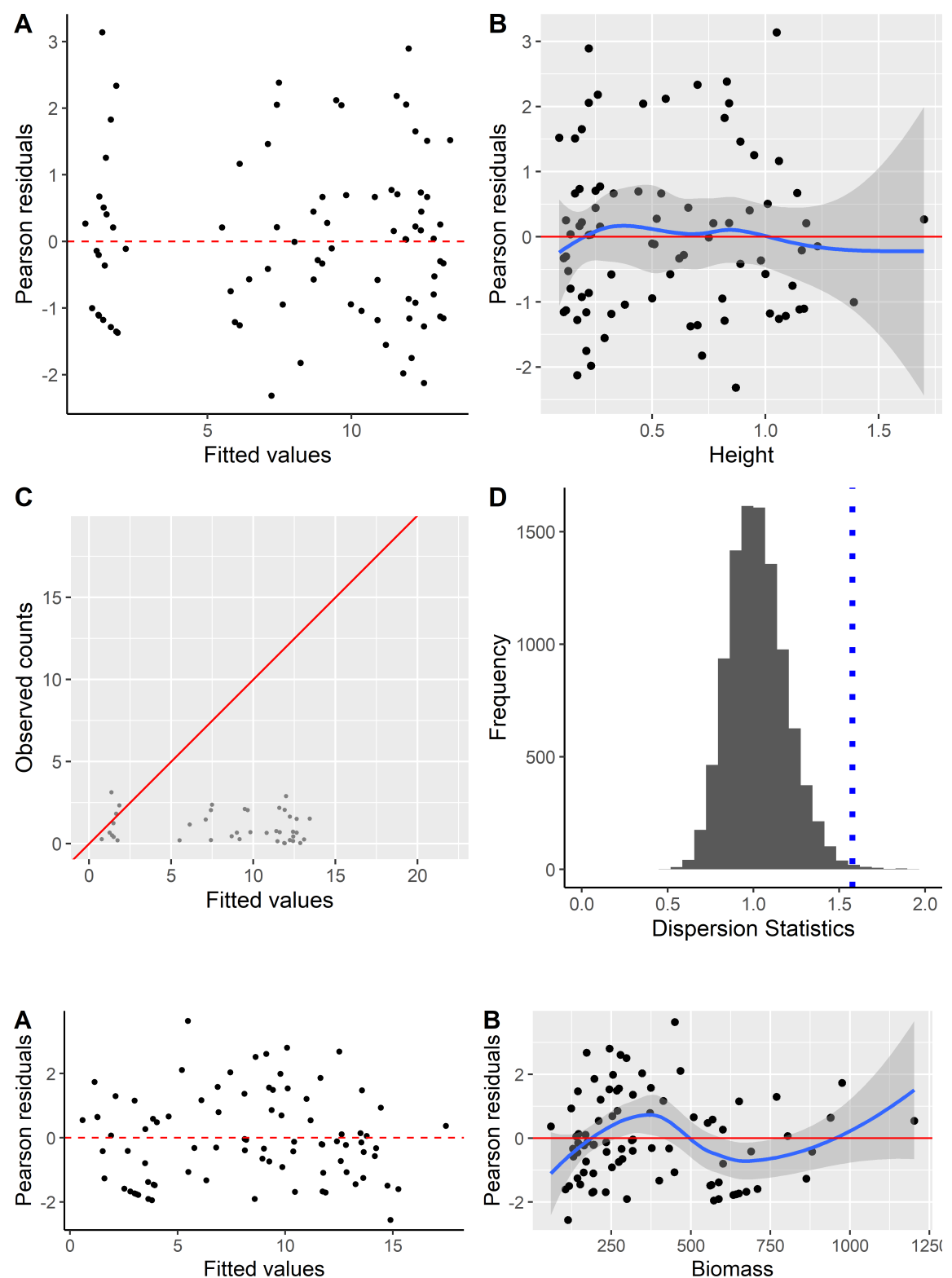

C

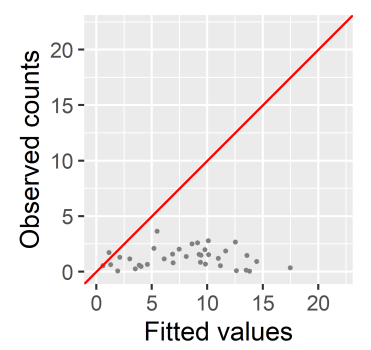

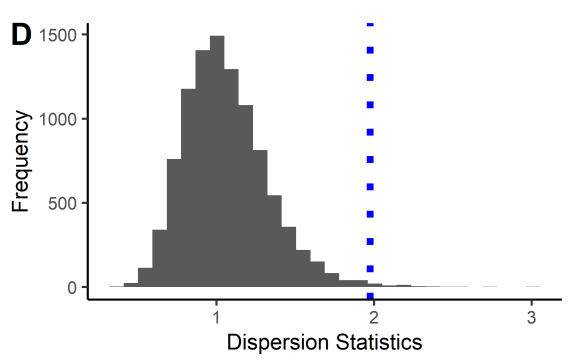



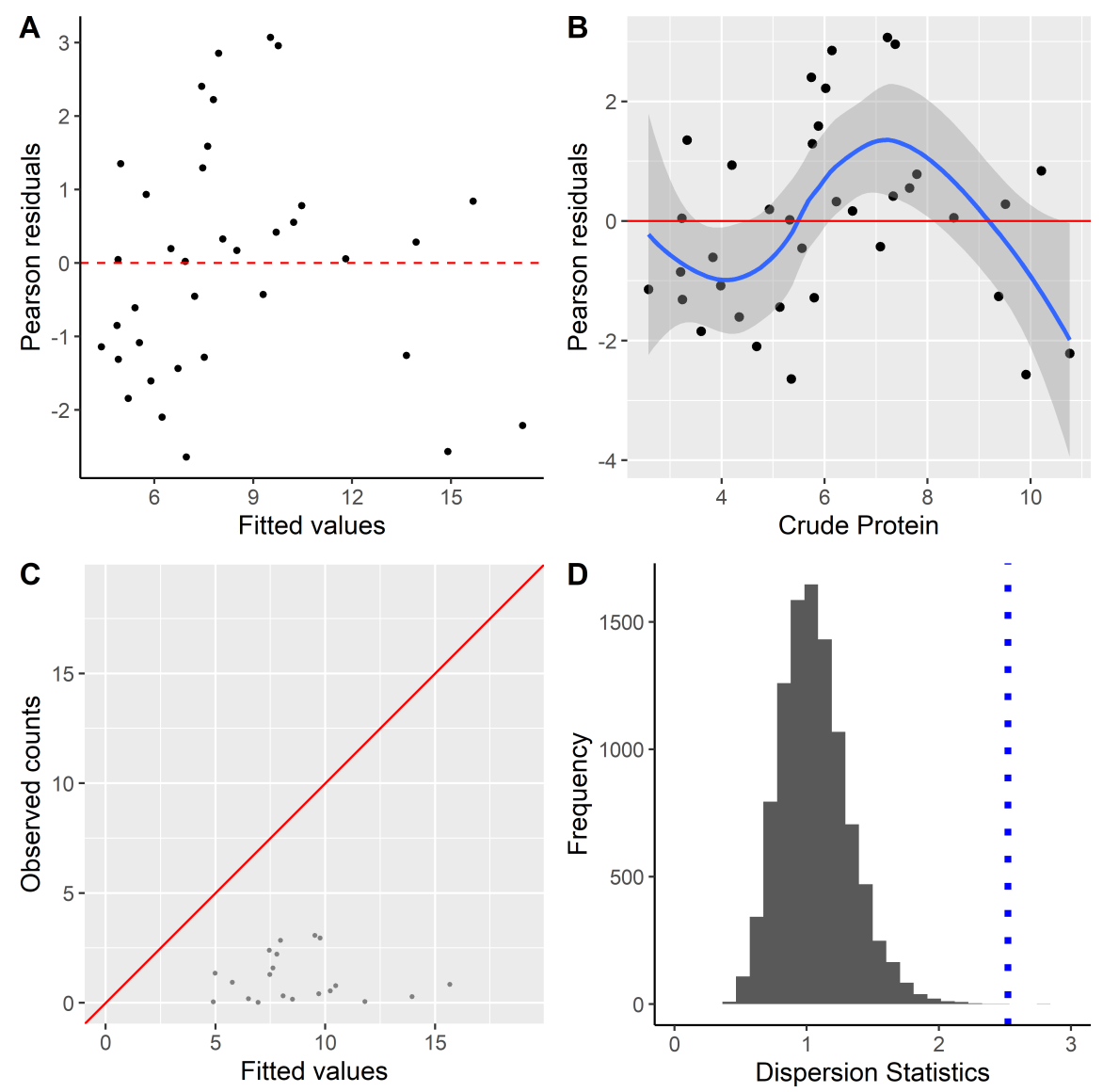